\title{
The Word Sort: An instrument for semantic analysis'
}

DANHY D. STEINBERG

EDUCATION RESEARCH AND DEVELOPMENT CENTER, UNIVERSITY OF HAWAII

An objective instrument is developed which provides reliable psychological data with reference to semantic denotative features or components. The instrument, the Word Sort, is in the form of an individual word game in which $S s$ are instructed to arrange words into a number of groups according to some meaningful principle. Kinship terms were provided $21 \mathrm{Ss}$ for dimensionalizing. Relatively high agreement among $S s$ was found with respect to the determination of semantic features.

While psychologists have dealt with some degree of effectiveness with the measurement problems of semantic connotation or affective meaning, particularly through the Semantic Differential technique (Osgood, Sucl, \& Tannenbaum, 1957), the measurement problem concerning another extremely important aspect of meaning, denotation, has held little attention for them. However, investigations in semantic denotation have been pursued by linguists and anthropologlsts, primarlly through subjective analyses of small sets of interrelated terms. English kinship terminology, for example, has been typically described with three distinctive features or semantic components: sex, generation, and lineality (Wallace \& Atkins, 1960). Such an analysis, where a particular set of words is defined in terms of the same semantic dimensions or components, is typically called a "componential analysis" (Brown, 1965).

Although the results of a componential analysis may be legitimately used as a source of hypotheses for later empirical testing (witness the work of Romney \& D'Andrade (1964)), such results may not be regarded as more than hypothetical. The position of Goodenough (1956), Wallace \& Atkins (1960), and others that such descriptions in addition to representing a set of terms in a most economical and systematic manner, also represent basic psychological structures is certainly an untenable one. The findings of componential analyses are necessarily equivocal from a scientific point of view since the investigator employs a subjective method of analysis to his data. He has no objective procedure at his disposal for determining components. The present work attempts to develop an objective instrument that can provide reliable psychological data with reference to semantic dimensions or components.

Subjects

Twenty-one students, ranging in age from 17 to 21 years, were obtained from an introductory psychology course at the University of Hawail.

\section{The Word Son}

The Word Sort consists of a number of terms, each on a separate plece of paper which the $S$ is instructed to arrange into groups according to some meaningful principle. The meaningful principle utilized is not required to be one that the $S$ can verbalize. The $S$ is encouraged to make as many meaningful sorts as possible. The Word Sort has features similar to the Vigotsky Block Test and to a semantic word game which Osgood is developing. 2

Procedure

Each $S$ was given an instruction sheet and $151 / 2 \mathrm{x}$ 1 in. pieces of paper with a printed word on each. The 15 words were father, mother, son, daughter, brother, sister, uncle, aunt, nephew, niece, cousin, grandfather, grandmother, grandson, and granddaughter. A basic portion of the instructions presented follows:

"Your task is to sort the 15 words into piles on the basis of some aspect of meaning. The aspect of meaning which you select is entirely up to you. I don't even want to know what the basis is. You do not need to verbalize your meaning dimension. You may not even know what it it is yourself!

(1) Sort the words into piles on the basis of some aspect of meaning (2) $\mathrm{mix}$ the 15 words up again and...sort the words again. This time, however, you must use a different basis of meaning (3) repeat this procedure as many times as you can. Remember, you may have a minimum of two piles of words and a maximum of 15 piles, and you may have from 1 to 14 words in a pile."

About 30 min later, when most Ss had finished writing, time was called. The $\mathrm{E}$ then distributed lined sheets and asked Ss to write down, if they could, a description of the meaningful dimension on which each of their solutions had been based. Total administration time was approximately $50 \mathrm{~min}$.

With respect to scoring, the frequency of identical solutions across Ss was tabulated. (The serial order of terms or groups was not considered.) An exception to the scoring procedure was made for the term "cousin" which was not counted as a member of any particular group since it often tended to combine with many groups almost randomly, thus making every solution given appear unique.

Resulis

A total of 187 different solutions were produced by all $21 \mathrm{Ss}$, an average of nearly nine different solutions per S. The most frequently occurring solutions, 1.e., 
Table 1

Frequently occurring word sort solutions

\begin{tabular}{|c|c|c|c|}
\hline \multicolumn{2}{|c|}{ Total No. of $S_{s}=21$} & \multicolumn{2}{|c|}{ Total No. of Solution $s=187$} \\
\hline \multirow{3}{*}{\multicolumn{2}{|c|}{ Groups of Kin Terms }} & No. of $S_{s}$ & $\%$ Ss \\
\hline & & who gave & who gave \\
\hline & & Solution & Solution \\
\hline \multirow{8}{*}{\multicolumn{2}{|c|}{$\begin{array}{l}\text { Solution } 1 \text { (a) brother, sister } \\
\text { (b) son, daughter } \\
\text { (c) father, mother } \\
\text { (d) uncle, aunt } \\
\text { (e) nephew, niece } \\
\text { (f) grandfather, grandmother } \\
\text { (g) grandson, granddaughter } \\
\text { (h) cousin* }\end{array}$}} & 20 & 95.3 \\
\hline & & & \\
\hline & & & \\
\hline & & & \\
\hline & & & \\
\hline & & & \\
\hline & & & \\
\hline & & & \\
\hline \multirow{3}{*}{\multicolumn{2}{|c|}{$\begin{array}{l}\text { Solution } 2 \text { (a) all male terms } \\
\text { (b) all female terms } \\
\text { (c) cousin }{ }^{\star}\end{array}$}} & 20 & 95.3 \\
\hline & & & \\
\hline & & & \\
\hline \multirow{5}{*}{\multicolumn{2}{|c|}{$\begin{array}{l}\text { Solution } 3 \text { (a) grandmother, grandfather } \\
\text { father, mother, aunt, uncle } \\
\text { (b) brother, sister, daughter, son } \\
\text { niece, nephew, granddaughter, } \\
\text { grandson, cousin }\end{array}$}} & 8 & 38.1 \\
\hline & & & \\
\hline & & & \\
\hline & & & \\
\hline & & & \\
\hline \multirow{6}{*}{\multicolumn{2}{|c|}{$\begin{array}{l}\text { Solution } 4 \text { (a) grandfather, grandmother, } \\
\text { granddaughter, grandson } \\
\text { (b) father, mother, daughter, son } \\
\text { (c) aunt, uncle, niece, nephew } \\
\text { (d) brothers, sister } \\
\text { (e) cousin* }\end{array}$}} & 7 & 33.3 \\
\hline & & & \\
\hline & & & \\
\hline & & & \\
\hline & & & \\
\hline & & & \\
\hline
\end{tabular}

* Sometimes occurred with other groups.

solutions which occurred more than once, are shown in Table 1. The number and percentage of Ss who obtained each of these four most frequent solutions are also indicated in the table. Thus, Solutions $1,2,3$, and 4 were obtained by $95.3 \%, 95.3 \%, 38.1 \%$, and $33.3 \%$ of the Ss, respectively. Since the probability of any one solution occurring is astronomical, all four solutions may be regarded as statistically significant, i.e., not likely due to sampling error. The four solutions account for approximately $30 \%(55 / 187)$ of all solutions given.
In their written reports, Ss were largely unable to state the basis upon which they had constructed their solutions. Substantial agreement occurred only in the case of Solution 2, where Ss indicated that a sex factor was operating.

\section{Discussion}

The solution findings exhibit both similarity and differences with respect to the typically extracted componential analysis features of sex, generation, and lineality (Wallace \& Atkins, 1960). The features of sex (Solution 2) and generation (Solution 3) distinctly appear in the solution outcomes. (For generation, a two-way split is made between older and younger generations.) However, lineality apparently occurs only when in interaction with other features. An interaction of both lineal and generation dimensions would account for the occurrence of Solution 4; Solution 1 seems to consist of conjugal and slbling sex pairs that are delineated on the basis of generation and degrees of lineality. Of the preceding interpretations, only the description of a dimension of sex for Solution 2 receives definite support from the written reports of the Ss.

The relatively high agreement found between Ss with respect to four different solutions and the relatively high proportion of the total number of solutions which they represent seem to offer some validity for the Word sort as an instrument for semantic inquiry.

\section{References}

Brown, R. Social psychology New York: Free Press, 1965.

Goodenough, W. Componential analysis and the study of meaning. Language, 1956, 32.

Osgood, C. E., Suci, i. J., \& Tannenbaum, P. H. The measurement of meaning. Urbana. Illinnis: University of Illinois Press, 1957.

Romney, A. K., \& $\mathbf{D}$ Indrark, R. W. Transcultural studies in cognition. Amer. Anthropologist, 1964, 66, No. 3, 2.

Wallace, A. F. C., \& Atkins, J. The meaning of kinship terms. Amer. Anthrolog: $t, 1960,62$.

\section{Notes}

1. The autho great! ben: : ted from the interdisciplinary criticisms of Char!-s E. r rool sychologist), Edwin Cook (anthropologist) and Geoige Grawe (linguist).

2. Personal conunic tion fom Charles E. Osgood. 